\title{
Description of a Minimally Invasive Technique to Correct a Gingival Margin Defect: A Case Report
}

\author{
Pandya $\mathrm{N}^{1}$, Turner $\mathrm{W}^{1,2}$ and Gillam DG ${ }^{1 *}$ \\ ${ }^{1}$ Institute of Dentistry, Barts and the London School of Medicine and Dentistry, Queen Mary University London, UK \\ ${ }^{2}$ Centre for Dentistry, School of Medicine, Dentistry and Biomedical Science, Queen's University Belfast, UK
}

Submission: June 26, 2020; Published: July 06, 2020

*Corresponding author: David G Gillam, Oral Bio Engineering Institute of Dentistry Barts and the London School of Medicine and Dentistry Queen Mary University London, UK

Abstract

This paper describes a case report using a Minimally Invasive Surgical Technique in a patient who was referred for the assessment and treatment of gingival recession and associated aesthetic concerns.

Keywords: Gingival recession; Marginal gingival defect; Periodontal surgery; Minimally invasive surgical technique

\section{Case Report}

\section{History and presenting clinical features}

A 53-year-old female patient who regularly attended her dentist for a general dental check-up which included threemonthly hygienist appointments was referred to a periodontal specialist (NP) regarding her concerns about the aesthetics in the UL1-UL5 area.

\section{Relevant Medical and Dental History}

There was no relevant Medical History, she was a non-smoker and did not drink any alcohol. On examination it was noted that her oral hygiene was good and she intimated that she brushed her teeth twice daily using an Oral B powered toothbrush with a fluoride toothpaste as well as a mouth rinse on a daily basis; flossing was only occasionally performed.

\section{Main Complaint}

In the absence of any symptoms (e.g., dentine hypersensitivity) the patient's main concern was related to the unsightly aesthetics on the buccal surface of UL1 which had been present for several years although she thought that the recession had worsened more recently.

\section{Clinical Examination}

On further examination, it was noted that there were minimal probing depths, plaque and, calculus deposits although there was gingival recession present on the buccal surfaces of UL1, UL, 3 and UL 4 ranging from $1-4 \mathrm{~mm}$ (Figure 1).

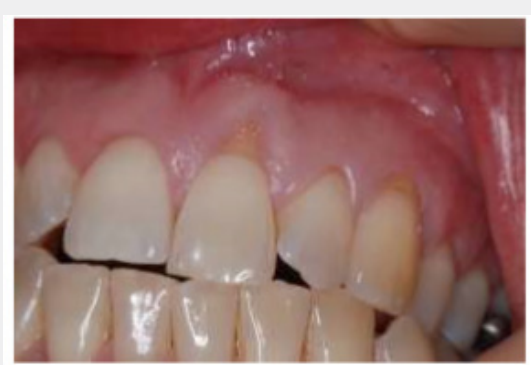

Figure 1: Clinical photograph of gingival recession on the anterior teeth.

\section{Surgical Procedure}

Following informed and written consent by the patient, an appointment was made for periodontal surgery. The site (UR1UL5) was successfully anaesthetised using buccal and palatal infiltrations (2.2ml Septanest 1;1000,000 [Articaine Hydrochloride with adrenaline]). A minimally invasive surgical technique as described by Allen [1] using crevicular incisions to raise a buccal flap with a surgical blade $($ no; 15$)$ was used in the procedure. There were no vertical relieving incisions. The exposed root surfaces of the teeth in question (mainly UL1 and UL3) were debrided using an ultrasonic scaler (Cavitron) to remove any plaque or calculus deposit; the procedure was completed by conditioning of the root surface with citric acid and ethylenediaminetetraacetic acid 
(EDTA) on the root surface. In order to preserve the interdental papillae and minimise any unnecessary trauma, the area was prepared to involve a tunnel procedure (buccal pouch) where two pieces of AlloDerm (BioHorizons IPH, Inc. Birmingham, AL USA) were placed within the space created by the pouch. A coronally advanced flap procedure was then used, and the flap secured using a modified continuous sling suture technique (6/0 Monofilament [Molypen]). An extra suture was place buccal to UL1 and a cyanoacrylate tissue glue (PeriAcryl ${ }^{\circledR 90}$ ) (GluStitch Inc, Delta, BC, Canada) was used to secure the flap, haemostasis was achieved. Overall, there were no problems encountered during the surgical procedure (Figure 2).

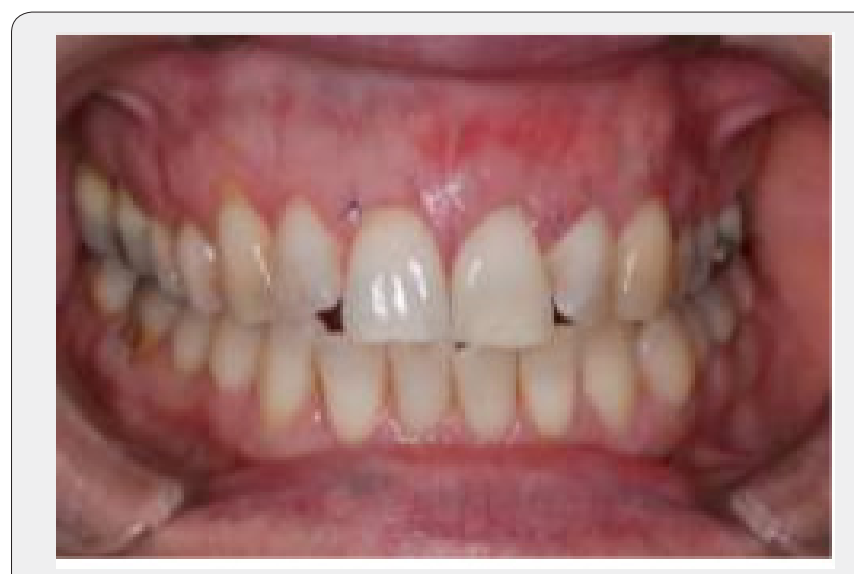

Figure 2: Clinical photograph immediately following the periodontal surgery, note the sutures in place with an additional interrupted suture securing the flap (UR1).

\section{Post-operative Instructions}

Post-operative instructions were provided to the patient which included advice on not to brush the upper arch, the patient was also advised to rinse her mouth using a $0.2 \%$ chlorhexidine gluconate mouth rinse twice daily for the two weeks. Two ice packs were provided to relieve any subsequent swelling as well as ibuprofen (400mg - 16 tablets [ 4 times a day for 4 days]) for pain relief. Antibiotics (Amoxycillin 500mg for five days) were also given to the patient who was then reappointed for subsequent appointments at two-week intervals for a review for 8-10 weeks (Figure 3). During this review period no problems were encountered. The sutures were removed 8 weeks post op and the patient was advised to brush normally with a soft brush (TePe soft surgical brush) for 4-6 weeks (Figure 4). The patient was monitored for every 2 weeks for next 1-2 months. At a subsequent review, clinical photographs were taken (Figures 5a, 5b). Healing of the surgical site was uneventful and, the patient maintained good oral hygiene during this period. The exposed root surface was successfully covered.
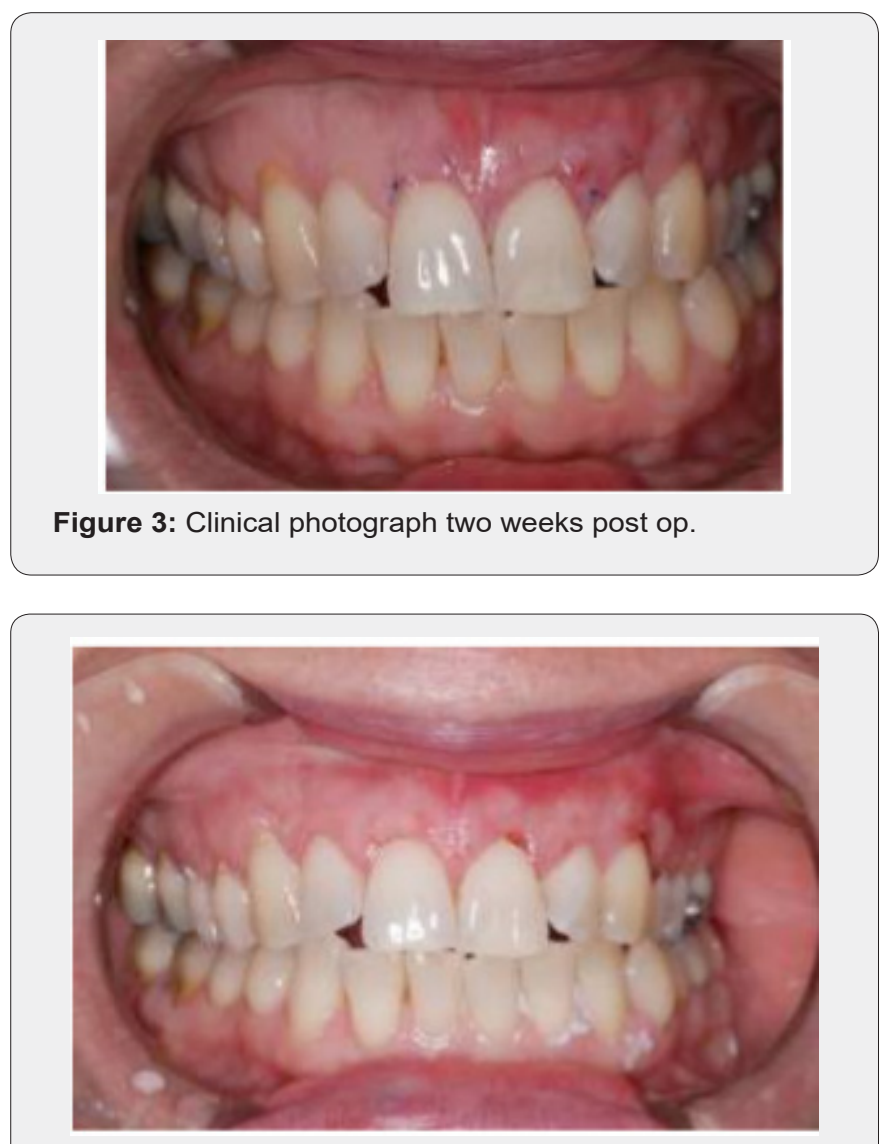

Figure 4: Clinical photograph of the surgical site at 8 weeks post op following suture removal.
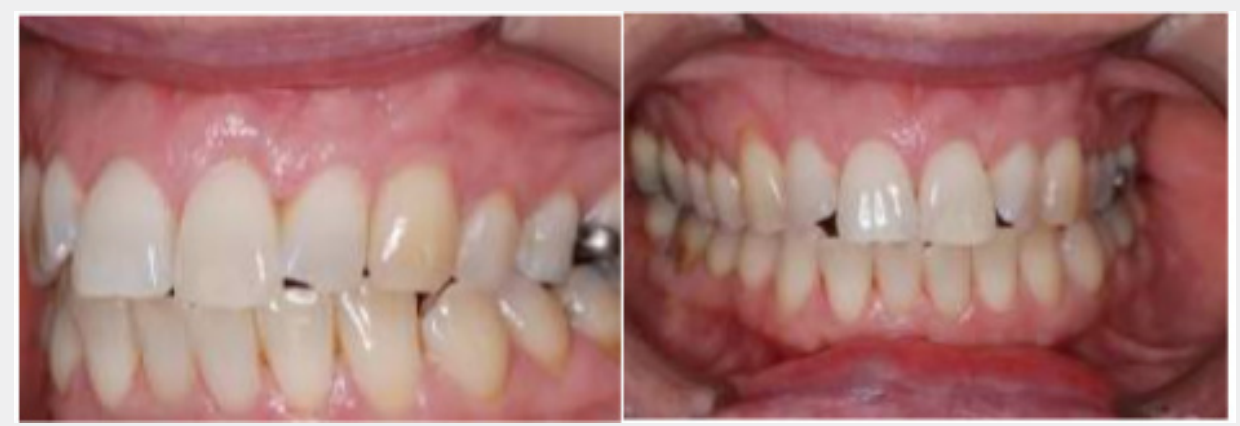

Figure 5a, b: Clinical photographs taken at a review appointment 2-3 months post op. 


\section{Patient Outcomes}

The patient was very pleased with the outcome from this procedure and was very happy with her appearance (Figure 6).

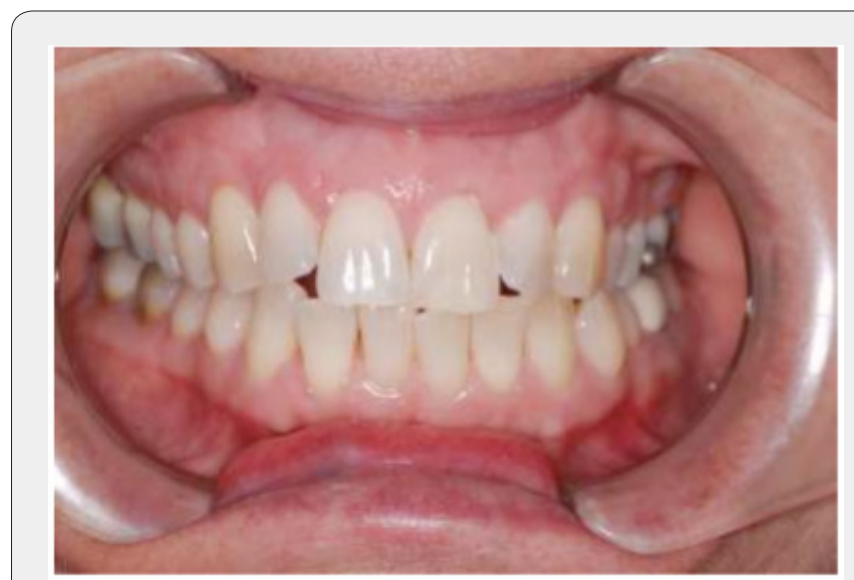

Figure 6: Clinical photograph 5 months post op.

\section{Conclusion}

Although this case report provides an overview of a periodontal procedure using a minimally invasive approach to correct a marginal gingival defect (gingival recession) which aesthetically was unacceptable to the patient it is important to recognize the role of good communication in emphasizing the corrective oral hygiene measures and the benefits of non-surgical procedures. [24]. The patient in question was highly motivated and keen to have the problem resolved, from a periodontal aspect she was relatively healthy and her main concern was the aesthetics which is one of the main concerns that patients have when seeking dental treatment [5]. The surgical procedures (Papillary preservation, tunnel procedure and Coronally advanced flap) briefly outlined were designed to reduce any unnecessary trauma to the patient, to maintain the height of the papilla, rectify the marginal defect and to assist subsequent wound healing [1,6-10]. There is no doubt that improvement in both surgical techniques and innovative materials such as Alloderm and Enamel Matrix Derivatives in the last two decades have improved the predictability of the clinical outcomes of these periodontal procedures $[7,10]$. The outcomes as described in this case report clearly demonstrated the clinical management of the marginal defect to the satisfaction of the clinician involved but more importantly the outcome for the patient was that she was completely satisfied with the end result which gave her confidence in her social interaction as well an improvement in her Quality of Life (QoL) [11].

\section{References}

1. Allen AL (1994) Use of the supraperiosteal envelope in soft tissue grafting for root coverage. II. Clinical results. Int J Periodontics Restor Dent 14(4): 302-315.

2. Ashruff F (2016) Impact of Oral Hygiene Instructions in the Maintenance of Periodontal Health of Patients. J Pharm Sci \& Res 8(10): $1212-1214$

3. Axelsson P, Lindhe J (1981) Effect of controlled oral hygiene procedures on caries and periodontal disease in adults. Results after 6 years. J Clin Periodontol 8(3): 239-248.

4. Turner Y, Ashley FP, Wilson RF (1994) Effectiveness of oral hygiene with and without root planing in treating subjects with chronic periodontitis. Br Dent J 177(10): 367-367.

5. Zaher CA, Hachem J, Puhan MA, Mombelli A (2005) Interest in periodontology and preferences for treatment of localized gingival recessions. A survey among Swiss dentists. J Clin Periodontol 32(4): 375-382. 5 .

6. Cortellini P, Prato GP, Tonetti MS (1995) The modified papilla preservation technique. A new surgical approach for interproximal regenerative procedures. J Periodontol 66(4): 261-266.

7. Cortellini P, Prato GP, Tonetti MS (1999) The simplified papilla preservation flap: A novel surgical approach for the management of soft tissues in regenerative procedures. Int J Periodontics Restorative Dent 19(6): 589-599.

8. Cortellini P, Tonetti MS (2007) A minimally invasive surgical technique with an enamel matrix derivative in the regenerative treatment of intrabony defects: a novel approach to limit morbidity. J Clin Periodontol 34(1): 87-93.

9. Cortellini P, Tonetti MS (2009) Improved wound stability with a modified minimally invasive surgical technique in the regenerative treatment of isolated interdental intrabony defects. J Clin Periodontol 36(2): 157-163.

10. Tunnell, JC \&. Harrel, SK (2017) Minimally Invasive Surgery in Periodontal Regeneration: A Review of the Literature. Compend Contin Educ Dent 38(4): e13-e16.

11. Shah EB, Modi BB, Shah MA, Dave DH (2017) Patient Centered Outcomes in Periodontal Treatment-An Evidenced Based Approach. J Clin Diagn Res 11(4): ZE05-ZE07. 
This work is licensed under Creative Commons Attribution 4.0 License

DOI: 10.19080/ADOH.2020.13.555851
Your next submission with Juniper Publishers will reach you the below assets

- Quality Editorial service

- Swift Peer Review

- Reprints availability

- E-prints Service

- Manuscript Podcast for convenient understanding

- Global attainment for your research

- Manuscript accessibility in different formats

( Pdf, E-pub, Full Text, Audio)

- Unceasing customer service

Track the below URL for one-step submission https://juniperpublishers.com/online-submission.php 